Federal Reserve Bank of Minneapolis

Research Department Staff Report 447

June 2010

\title{
Comment on Christian's
}

\section{"Human Capital Accounting in the United States: 1994-2006"*}

Ellen R. McGrattan

Federal Reserve Bank of Minneapolis

and University of Minnesota

\begin{abstract}
Michael Christian's paper presents a human capital account for the United States for the period 1994 to 2006. The main findings are twofold. First, the total human capital stock is about three-quarters of a quadrillion dollars in 2006. This estimate is roughly 55 times gross domestic product (GDP) and 16 times the net stock of fixed assets plus consumer durables. His second finding is that the measures of gross investment in human capital are sensitive to alternative assumptions about enrollment patterns. In my comments, I emphasize the need for greater interaction between human capital accountants and applied economists. To date, there remains a disconnect between those measuring human wealth and those investigating its economic impact.

* This discussion of Michael Christian's paper was prepared for the Bureau of Economic Analysis Advisory Committee meeting in May 2010. The views expressed herein are those of the author and not necessarily those of the Federal Reserve Bank of Minneapolis or the Federal Reserve System.
\end{abstract}




\section{Introduction}

Michael Christian's paper presents a human capital account for the United States for the period 1994 to 2006. The human capital stock measure is equal to the lifetime labor incomes of the U.S. population. The total stock can be divided into a market component and a nonmarket component. The market component is the present discounted value of lifetime earnings from market work. The nonmarket component is the present discounted value of time in activities outside of work and school. It is assumed that the value of nonmarket time is the value of market time adjusted by the marginal tax rate on labor.

In my comments, I emphasize the need for greater interaction between human capital accountants and applied economists. To date, there remains a disconnect between those measuring human wealth and those investigating its economic impact.

\section{Main Findings}

Christian's main findings are twofold. First, the total human capital stock-including the value of market and nonmarket components - is about three-quarters of a quadrillion dollars in 2006. This estimate is roughly 55 times GDP and 16 times the net stock of fixed assets plus consumer durables. His second finding is that the measures of gross investment in human capital are sensitive to alternative assumptions about enrollment patterns.

Christian applies the methodology of Jorgenson and Fraumeni (1989,1992), who estimate the present discounted value of the future stream of earnings to investment in human capital. ${ }^{1}$ To keep things simple, assume that death is certain after age 80 . Then, starting with the oldest age group considered (which is 80 ), the human capital for someone is the

1 One innovation of Christian's paper is the handling of a change in the Current Population Survey (CPS) which now asks individuals what degree they earned rather than the number of school years they completed. 
average yearly earnings of people with the same sex and education level. Working backwards, the human capital of the second oldest age group (which is 79) is calculated as the average yearly earnings of people with the same sex and education level plus the present value of future earnings. Continuing recursively, the stock is constructed as follows:

$$
H_{y, s, a, e}=E_{y, s, a, e}+\frac{(1+g)}{(1+\rho)} \pi_{y, s, a+1} H_{y, s, a+1, e}
$$

where $y$ denotes year, $s$ denotes sex, $a$ denotes age, $e$ denotes education level, $E$ is average yearly earnings, $H$ is the stock of human capital, $\pi$ is the survival probability, $g$ is the growth rate of labor income, and $\rho$ is the rate of discount. The same calculation can be done for the nonmarket component of human capital. Christian assumes that nonmarket hours earn the same after-tax wage rate as market hours.

The calculations are slightly more complicated for younger age groups, since some people may not have completed all of their schooling. In this case, the term $H_{y, s, a+1, e}$ on the right-hand side of (2.1) is replaced by a weighted sum of $H_{y, s, a+1, e}$ and $H_{y, s, a+1, e+1}$, where the weight depends on the probability of someone with characteristics $(s, a, e)$ enrolling for another year.

The results of Christian's calculations are shown in Figure 1. Here, I have divided the stocks by GDP in order to see how they have varied across time. The top line is the total stock, which is about 59 times GDP in 1994 and 55 times GDP by 2006. The market and nonmarket components are also shown. The market component is slightly under 30 percent of the total human capital stock; this estimate is consistent with discretionary time allocation to market activities reported in time use studies. The bottom line in the figure is the ratio of fixed assets and durables to GDP, which is a typical reference point for human wealth accountants. The ratio of fixed assets plus durables to GDP is slightly 
over 3, which is much smaller than either the ratio of nonmarket human capital to GDP or the ratio of market human capital to GDP shown in Figure 1.

Figure 2 compares the total human capital estimates of Christian with the earlier work of Jorgenson and Fraumeni $(1989,1992)$ and Kendrick (1976). ${ }^{2}$ In their 1989 study, Jorgenson and Fraumeni compute estimates of human capital that are on average 55 times GDP. This is close to what Christian finds for the 1994-2006 period. The later 1992 study of Jorgenson and Fraumeni finds estimates that are 64 times GDP on average. The lower line on Figure 2 is Kendrick's (1976) measure of the human capital stock relative to GDP. Kendrick bases his measure on costs of inputs to formal education like teacher time and books. His estimates are 3.5 times GDP on average. The Jorgenson and Fraumeni estimates are 16 to 18 times larger. ${ }^{3}$ Interestingly, the difference between the two Jorgenson and Fraumeni series of 1989 and 1992 is larger than either Kendrick's measure or the ratio of fixed assets plus durables to GDP shown in Figure 1.

The second main finding of Christian's study is that gross investment estimates are sensitive to assumptions about future enrollment decisions of individuals. Gross investment in education for a particular person and year is the difference in lifetime earnings for one more year of schooling. To compute gross investment, Christian must specify future choices of those currently enrolled and future choices if the same people had not enrolled in school. For two extreme scenarios, Christian finds that his gross investment estimates are different by roughly a factor of five. The first he calls the "on track" scenario: students that miss

2 The estimates in Figure 2 for Jorgenson and Fraumeni $(1989,1992)$ and Kendrick (1976) include only private sector human wealth. The underlying data for the three studies are reported in Table 5.35 of Jorgenson and Fraumeni (1989) and Table 8.17 of Jorgenson and Fraumeni (1992).

${ }^{3}$ In theory, the lifetime income approach of Jorgenson and Fraumeni $(1989,1992)$ and the cost-based approach of Kendrick (1976) should yield a different estimate for the stock of human capital; the ratio of the two estimates is the price of capital, which is analogous to Tobin's Q for corporate capital. However, estimates of prices on the order of 16 to 18 for the human capital stocks are much larger than typical estimates of Tobin's $Q$, which have been in the range of $1 / 2$ to 2 over the post-World War II period. 
a year of school pursue further education with the same probabilities they would have if they had not missed a year. The second he calls the "off track" scenario: students that miss a year of school behave like people who actually did miss a year of school. These two scenarios imply very different estimates for the market component of gross investment in human capital, which is estimated to be about 20 percent of GDP in 2005 for the "on track" case and about 120 percent of GDP in the "off track" case.

\section{Discussion}

I enjoyed reading Christian's paper and the papers of Jorgenson and Fraumeni upon which it builds. It was interesting to contrast this work with Kendrick's (1976) earlier work and to see how the different approaches lead to such different estimates for human wealth. What I find most surprising, however, is the disconnect between the work on the human capital accounts and almost all applied work in labor, development, finance, and macroeconomics. A priori, I would have thought that users of the accounts would extend well beyond the satellite accountants themselves. In this section, I hypothesize that the source of the disconnect in the two literatures is the fact that the accountants focus almost exclusively on the size of the capital stock estimates and hardly at all on the ultimate questions they hope to address with the accounts.

\subsection{Less Focus on the Size of the Stock}

Abraham (2010) and others before her ${ }^{4}$ present a long list of reasons why the estimates of human capital based on the Jorgenson-Fraumeni methodology — which Christian uses — are so large and why there is "underlying discomfort with the magnitude" of the estimates.

\footnotetext{
4 See, for example, Rosen (1989) and Rothschild (1992).
} 
Almost every commentator of the Jorgenson-Fraumeni methodology points out that human capital estimates are large because the imputed value of nonmarket time is the after-tax wage rate, which may be implausibly high. Rosen (1989) also highlights the fact that the costs of raising children and maintaining the stock during the working life are not netted out, implying an asymmetric treatment of human and nonhuman capital. Choices of discount rates, which may be too low, and growth rates, which may be too high, can also bias the results.

What these commentators do not really discuss is why any of this matters. What are the economic questions these estimates can help us answer? What if Christian's estimates were 10 times bigger or, alternatively, 10 times smaller? What results will be overturned if we use the Christian-Jorgenson-Fraumeni estimates versus the Kendrick estimates?

At this point, I suspect that few, if any, have an answer to these questions. Most citations of the human capital accounts simply point out that the estimates of human wealth are large (regardless of how they are constructed) and, therefore, neglecting them has a big impact on wealth and income accounts. ${ }^{5}$ But, for the most part, researchers citing the human capital accounts are not actually using the estimates as an intermediate input in their own work.

\subsection{More Focus on Economic Questions}

Perhaps what is needed is more focus on economic questions and less focus on the magnitudes of the human capital wealth estimates. Whether these estimates are based on current costs or on lifetime earnings, economists can construct the same statistics in their

5 For example, in his presidential address for the American Economic Association, Gary Becker (1988) surmises that "the true ratio of human capital to the total capital stock may be as high as 90 percent or as low as 50 percent. Of course, even this lower percentage signifies a large contribution." 
model economies as satellite accountants construct for actual data. Unfortunately, there still remains a great divide between those measuring human wealth and those investigating its economic impact. Here, I will discuss several research areas where there may be some fruitful synergies.

A priori, I expected to see a much stronger connection between the research on the human capital accounts and research on the economic impact of education. For example, in a survey of studies of the return to education, Card (2001) summarizes econometric estimates from regressions of earnings on schooling (which is a slightly more general version of the regression proposed by Mincer (1974)). I found no discussion of how the surveyed results compare with returns to education implied by the human capital accounts. Similarly, I found no discussions by the human capital accountants relating their estimates - either of total investment or even just market investment - to the regression results surveyed by Card.

In comparing the impact of schooling on growth performance across countries, Hanushek and Kimko (2000) use international math and science test scores as a measure of labor quality. They note that an alternative measure of labor quality is the human capital stock based on lifetime earnings, which could in principle be used instead, but I found no comparable cross-country studies. ${ }^{6}$ Obviously, the wealth of nations will change dramatically if we include values of human capital on the order of 55 times GDP. However, if one assumes that all time has an implicit value equal to the observed after-tax wage, relative comparisons of wealth, incomes, and productivity across nations may not change.

I also expected a stronger connection between research on the human capital accounts

6 Some work has begun to construct human capital accounts in a few countries. See, for example, OECD (2008). 
and the finance literature. A growing body of work within finance explicitly introduces human wealth in portfolios of asset-pricing models. A variety of assumptions are made about the returns to investment in human wealth. Shiller (1995) assumes the expected return is constant. Campbell (1996) assumes the expected returns on human wealth and financial wealth are perfectly correlated. Jagannathan and Wang (1996) assume that the expected return on human wealth is perfectly correlated with the expected labor income growth.

Lustig and Van Nieuwerburgh (2008) show that none of these assumptions about returns to human wealth are consistent with observed moments for consumption. They, therefore, back out the returns to human wealth using aggregate consumption data and find that they need to be negatively correlated with returns to financial assets in order to rationalize consumption patterns. Their result puts Christian's (2010) assumption of a constant discount rate into question. However, besides generating the observed patterns in consumption, it is not obvious what the full quantitative impact would be of relaxing this assumption.

Palacios-Huerta (2003) considers the role of risk in human capital investment using data on individual earnings to construct returns to human capital. His methodology is conceptually the same as Jorgenson and Fraumeni (1992), but no connection is made between the two sets of estimates of the human capital stocks or returns.

Finally, because I am a little more familiar with business cycle research, I am sorry to report that the connections with the human capital accounts are weak there too unless we focus narrowly on firm-specific human capital that earns rents for corporate shareholders 
and unincorporated business owners. Prescott and I (forthcoming) found that incorporating firm-specific intangible investment - nonhuman and human - into an otherwise standard business cycle model resolved a puzzle that we struggled with for several years. In the 1990s, corporate profits were falling while output was rising, and compensation per hour was falling while hours were booming. The low factor incomes during a period of increased economic activity were suggestive that investments in R\&D and advertising - that are expensed from corporate profits - and investments of time by business owners - that are expensed from compensation — were abnormally high. ${ }^{7}$

To test the hypothesis that the puzzling patterns were due to abnormally large intangible investments, we allowed for differential rates of technological change in production of final goods and services and production of intangible investment goods. Assuming that households equate wages and rental rates across production activities, we had a way to identify the paths of total factor productivity (TFP) in our model's two sectors and to estimate the magnitude of intangible investment. We fed those TFP paths into our model to see whether or not the model time series for GDP, hours, and tangible investment were close to the U.S. time series. We found that they were.

In our study, we abstracted from investments in human capital that earn rents to workers other than the business owners. However, it is possible that unmeasured human capital investment may be the source of what many macroeconomists call the "labor wedge." 8 The labor wedge is the unexplained gap in the intratemporal condition of the standard growth model (which equates the marginal rate of substitution between consumption and leisure and the marginal product of labor). Is it a preference shock? Is it due to variations in price

\footnotetext{
7 Direct measures of some of these expenditures made by Corrado, Hulten, and Sichel (2005,2006) also showed an increase over the 1990s.

8 See, for example, Chari, Kehoe, and McGrattan (2007) and Shimer (2009).
} 
and wage markups? Or is it due to variations in human capital investment that somehow are not being captured in the national accounts that we work with?

\section{Recommendations for Future Research}

In addition to focusing more on key economic questions, I recommend that future research be more specific about the underlying assumptions of the economic environment. Estimates of the stock of human capital depend on assumptions about preferences, technologies, and transactions. I would recommend more transparency by making the choices explicit in the context of a theoretical model. Furthermore, a clear distinction should be made between variables in our models and statistics that the Bureau of Economic Analysis (BEA) reports. As I noted earlier, the same methodology used by the BEA to construct the U.S. accounts can and should be used to construct the model accounts.

With a fully specified model in hand, we can begin to address many interesting economic questions.

\section{Conclusions}

In a workshop at the Brookings Institution, Fraumeni (2000) acknowledged that "the profession has been largely silent" about the conceptual and methodological features of the Jorgenson-Fraumeni approach that Christian (2010) is using to construct human capital accounts for the United States. She discussed some of the controversial choices that she and Jorgenson had made in an attempt to spur debate. In my opinion, more interaction between quantitative theorists and satellite accountants may better stimulate the debate she is seeking. 


\section{References}

Abraham, Katharine. 2010. "Accounting for Investments in Formal Education," Manuscript, University of Maryland.

Becker, Gary. 1988. "Family Economics and Macro Behavior," American Economic Review, $78(1)$ : 1-13.

Campbell, John. 1996. "Understanding Risk and Return," Journal of Political Economy, 104(2): $298-345$.

Card, David. 2001. "Estimating the Return to Schooling: Progress on Some Persistent Econometric Problems," Econometrica, 69(5): 1127-60.

Chari, V.V., Patrick J. Kehoe, and Ellen R. McGrattan. 2007. "Business Cycle Accounting," Econometrica, 75(3): 781-836.

Christian, Michael. 2010. "Human Capital Accounting in the US: 1994-2006," Manuscript, University of Wisconsin.

Corrado, Carol A., Charles R. Hulten, and Daniel E. Sichel. 2005. "Measuring Capital and Technology: An Expanded Framework," in Measuring Capital in the New Economy, ed. C. Corrado, J. Haltiwanger, and D. Sichel (Chicago: University of Chicago Press).

Corrado, Carol A., Charles R. Hulten, and Daniel E. Sichel. 2006. "Intangible Capital and Economic Growth," Finance and Economics Discussion Series, 2006-24, Federal Reserve Board, Washington, DC.

Fraumeni, Barbara M. 2000. "The Output of the Education Sector as Determined by Education's Effect on Lifetime Income," Manuscript, Brookings Institution.

Hanushek, Eric A., and Dennis D. Kimko. 2000. "Schooling, Labor-Force Quality, and the Growth of Nations," American Economic Review, 90(5): 1184-208.

Jagannathan, Ravi, and Zhenyu Wang. 1996. "The Conditional CAPM and the CrossSection of Expected Returns," Journal of Finance, 51(1): 3-53.

Jorgenson, Dale W., and Barbara M. Fraumeni. 1989. "The Accumulation of Human and Nonhuman Capital, 1948-84," in The Measurement of Saving, Investment and Wealth, ed. R. E. Lipsey and H. Stone Tice (Chicago: University of Chicago Press).

Jorgenson, Dale W., and Barbara M. Fraumeni. 1992. "The Output of the Education 
Sector," in Output Measurement in the Service Sectors, ed. Z. Griliches (Chicago: University of Chicago Press).

Kendrick, John W. 1976. The Formation and Stocks of Total Capital (New York: Columbia University Press).

Lustig, Hanno, and Stijn Van Nieuwerburgh. 2008. "The Returns on Human Capital: Good News on Wall Street Is Bad News on Main Street," Review of Financial Studies, 21(5): 2097-137.

McGrattan, Ellen R., and Prescott, Edward C. Forthcoming. "Unmeasured Investment and the Puzzling U.S. Boom in the 1990s," American Economic Journal: Macroeconomics.

Mincer, Jacob. 1974. Schooling, Experience, and Earnings (New York: Columbia University Press.)

Organisation for Economic Co-operation and Development (OECD). 2008. Workshop on the Measurement of Human Capital, Turin, Italy, November 3-4.

Palacios-Huerta, Ignacio. 2003. "An Empirical Analysis of the Risk Properties of Human Capital Returns," American Economic Review, 93(3): 948-64.

Rosen, Sherwin. 1989. "Comment on 'The Accumulation of Human and Nonhuman Capital, 1948-84' by Jorgenson and Fraumeni," in The Measurement of Saving, Investment and Wealth, ed. R. E. Lipsey and H. Stone Tice (Chicago: University of Chicago Press).

Rothschild, Michael. 1992. "Comment on 'The Output of the Education Sector,' by Jorgenson and Fraumeni," in Output Measurement in the Service Sectors, ed. Z. Griliches. (Chicago: University of Chicago Press).

Shiller, Robert. 1995. "Aggregate Income Risks and Hedging Mechanisms," Quarterly Review of Economics and Finance, 35(2): 119-52.

Shimer, Robert. 2009. "Convergence in Macroeconomics: The Labor Wedge," American Economic Journal: Macroeconomics, 1(1): 280-97. 


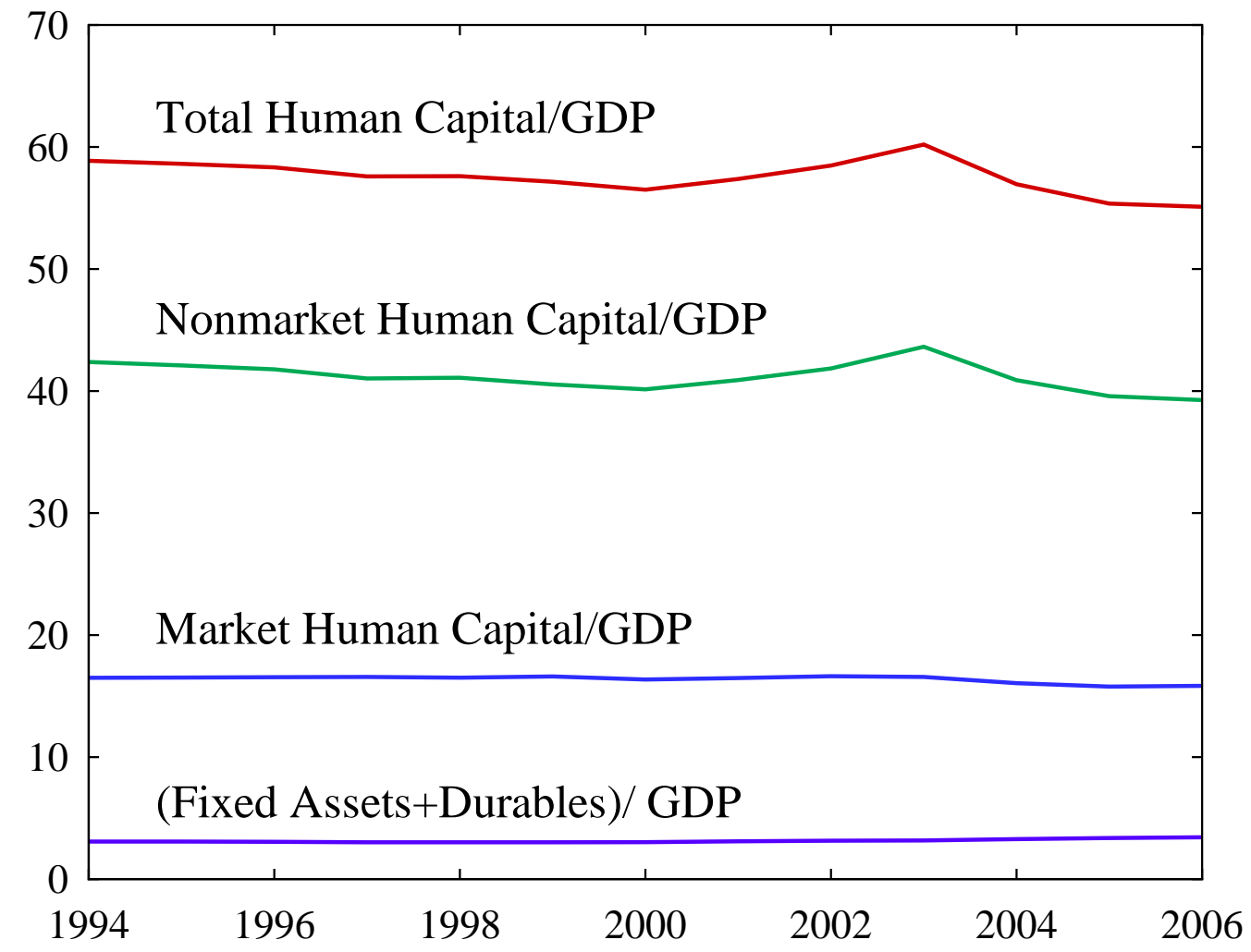

Figure 1. Human Capital Stocks Relative to GDP

Source: Christian (2010) 


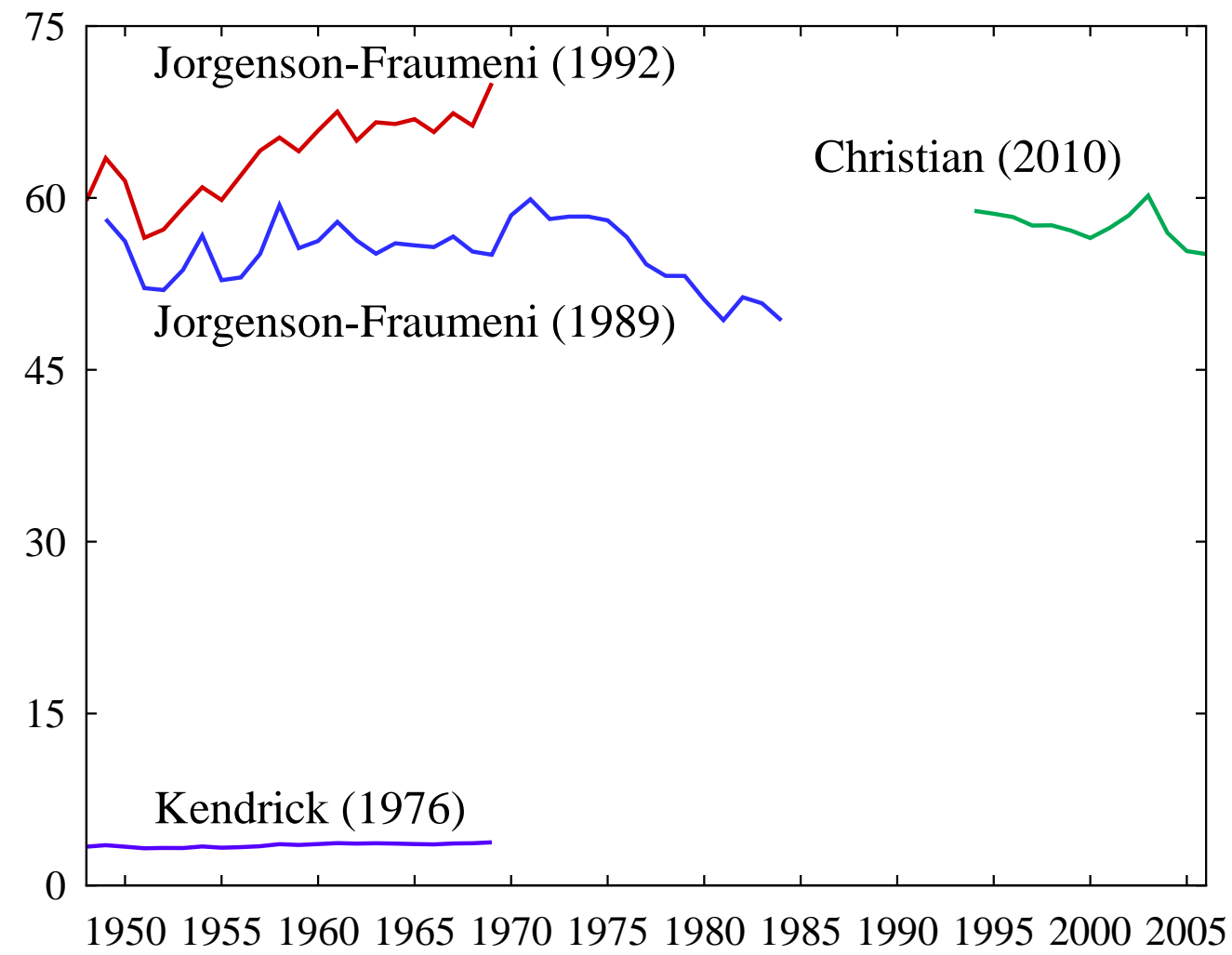

Figure 2. Human Capital Stocks Relative to GDP: Comparison Across Studies 